\title{
Evaluation of cyanobacterial cells removal and lysis by ultrafiltration
}

\author{
Margarida Campinas ${ }^{\mathrm{a}, *}$, Maria João Rosa ${ }^{\mathrm{b}}$ \\ a University of Algarve, Gambelas Campus, 8005-139 Faro, Portugal \\ b Urban Water Division, Department of Hydraulics and Environment, LNEC - National Civil Engineering Laboratory, Av. Brasil, 101, 1700-066 Lisboa, Portugal
}

\section{A R T I C L E I N F O}

\section{Article history:}

Received 17 April 2009

Received in revised form 23 October 2009

Accepted 28 October 2009

\section{Keywords:}

Microcystis aeruginosa

Ultrafiltration

Cell lysis

Microcystins

AOM

\begin{abstract}
A B S T R A C T
The aim of this study was to evaluate the ultrafiltration (UF) performance for removing Microcystis aeruginosa cells under different growth ages (1, 2, 3 and 4 months old). Special attention was given to cell damaging and subsequent release of microcystins to permeate. Experiments were performed with a hollow-fibre cellulose acetate membrane $(100 \mathrm{kDa})$. UF achieved an absolute removal of $M$. aeruginosa single cells, producing chlorophyll-a free water and with a turbidity below 0.1 NTU. Cell lysis occurred at all cell growth phases although greater damage was observed for older cultures. However, the permeate quality was never deteriorated and its microcystin concentration was always identical or lower than the dissolved concentration in the feed water. The hydrophilic UF membrane presented low adsorption of microcystins but the microcystin rejection increased in the presence of algogenic organic matter (AOM). The type rather than the overall concentration of salts and organics ruled the membrane fouling, the 1-month-old suspension (polysaccharide-rich AOM with scaling multivalent ions) presenting higher fouling potential than the 3-month-old suspension (protein-rich AOM with much lower content of multivalent ions).
\end{abstract}

(c) 2009 Elsevier B.V. All rights reserved.

\section{Introduction}

Cyanobacterial blooms seasonally challenge drinking water treatment due to the massive input of cells and also the release of algogenic organic matter (AOM) into the water, causing poor settling, filter clogging, tastes and odours, disinfectant consumption and production of disinfection by-products [1-3]. Nevertheless, the greatest environmental health concern arises from the ability of several cyanobacterial strains to produce potent toxins (cyanotoxins) as secondary metabolites, including cyclic peptide hepatotoxins (e.g. microcystins) and/or alkaloid neurotoxins (e.g. anatoxin-a). Microcystins are the most frequently occurring cyanotoxins, associated with the genera Microcystis, Anabaena, Planktothrix, Nostoc and Anabaenopsis, and may be liver damaging and tumour promoters [4]. The World Health Organization (WHO) derived a drinking water provisional guideline-value of $1 \mu \mathrm{g} / \mathrm{L}$ for daily exposure to the microcystin-LR, one of the most toxic and frequent microcystin variant.

Cyanotoxins may occur both within the cells (cell-bound or intracellular) or dissolved in water (extracellular), a feature that strongly influences their removal efficiency in drinking water

\footnotetext{
* Corresponding author. Permanent address: Urban Water Division, Department of Hydraulics and Environment, LNEC - National Civil Engineering Laboratory, Av. Brasil, 101, 1700-066 Lisboa, Portugal. Tel.: +351 218443617; fax: +351 218443032.

E-mail addresses: mgd.campinas@gmail.com (M. Campinas), mjrosa@lnec.pt (M.J. Rosa).
}

treatment plants. In general, if properly operated, conventional treatment (coagulation, flocculation, sedimentation and sand filtration) is able to control to some extent the cyanobacterial cells, but is ineffective for removing the extracellular cyanotoxins [5]. Toxin (and other organics) release into water may be due to natural phenomena (natural cell lysis or active release) and/or may result from cell damage during treatment caused by mechanical and/or chemical stresses (induced toxin release) [6]. The best treatment option is therefore to remove intact cyanobacterial cells [7] retaining the majority of metabolites inside the cells. While such strategy does not avoid further control of the dissolved organics naturally released to water (e.g. cyanotoxins and AOM), it definitely improves the overall effectiveness, safety and economics of the treatment process.

Cell lysis and AOM effects are actually the most controversial issues related with the algal cells removal by conventional treatment. While some studies refer the occurrence of cell lysis and release of intracellular material into water $[5,6,8]$ others report no effect on the cell integrity [7,9-11]. The use of oxidation prior to the clarification of algal-rich waters is also a matter of thorough sitespecific evaluation since its effects severely depend on the oxidant type and dose, as well as on the water characteristics [2]. Besides the problem of undesired by-products formation, oxidation may lyse the cyanobacterial cells $[1-3,6]$ and soluble toxin destruction is not always ensured.

Several authors have referred membrane filtration as an attractive technology to reach high removal efficiencies of algae $[6,8,12-14]$ applied either alone or following conventional clarifi- 
cation or DAF, depending on the raw water quality [13]. UF is a low-pressure process, ensuring effective disinfection. UF removal efficiencies are less affected by the raw water quality than the conventional treatment efficiencies, and an absolute removal of the cyanobacterial cells may be expected by UF given the relative size of the cells and the UF pores (usually two orders of magnitude lower) [12].

However and to our knowledge, only two studies were carried out on the removal of cyanobacterial cells by ultrafiltration. Chow et al. [12] used flat-sheet membranes operated in dead-end and crossflow modes to study the effect of membrane filtration on Microcystis aeruginosa cells. Their results showed that $99-100 \%$ of chlorophylla was removed, and only a small portion of cells were damaged by the treatment ( $c a .2-5 \%$ in dead-end operation and $4-10 \%$ in cross-flow operation) with no increase of toxin in the permeate. Gijsbertsen-Abrahamse et al. [14] used a hollow-fibre membrane operated in dead-end mode to determine the removal efficiency of cell-bound cyanotoxins of Planktothrix strains. Although microscopic measurements indicated slight damage of one-third of the $P$. agardhii filaments the damages were not considered substantial and corresponded to a maximum of $2 \%$ of cell-bound microcystin release detected in the permeate. However, to corroborate and complete these favourable findings, the same study recommends further investigation, particularly in what concerns the cell sensitivity to shear stress and the toxin release into water, phenomena that are both greatly affected by the cyanobacterial cell age.

In this context, the aim of this study is to evaluate the removal of laboratory grown $M$. aeruginosa cells under different growth ages by an UF hydrophilic hollow-fibre membrane, with $100 \mathrm{kDa}$ cutoff and operated in cross-flow mode. Particular attention is given to cell damaging and subsequent release of microcystins to the treated water, and also to membrane fouling by AOM. M. aeruginosa is one of the most commonly occurring cyanobacteria and grows in laboratory as single cells, which is an advantage for this study. Besides they better represent the size of algae that is more prone to escape from a conventional clarification process, $M$. aeruginosa single cells are a surrogate to assess the removal efficiency of particles of problematic size range $(3-10 \mu \mathrm{m})$, like Giardia cysts and Cryptosporidium oocysts.

\section{Experimental}

\subsection{Cyanobacterial culture and associated toxins}

M. aeruginosa culture (Pasteur Culture Collection, PCC 7820) was grown in the laboratory, in modified BG11 medium [15] (modification consisted on replacing iron and ammonia citrate by iron sulphate), at $23-24^{\circ} \mathrm{C}$, under a light regimen of $12 \mathrm{~h}$ fluorescent light, $12 \mathrm{~h}$ dark. Cultures were harvested at different growth ages determined from data in Section 2.2 in order to access distinct lysis vulnerabilities. This strain of $M$. aeruginosa produces four microcystin variants, MC-LR, -LY, -LW, -LF, and the overall concentration was quantified in $\mu \mathrm{g} / \mathrm{L}$ MC-LR $\mathrm{Lq}_{\mathrm{eq}}$ (Section 2.6). The studied microcystins are cyclic heptapeptides, relatively hydrophobic, with $985-1024 \mathrm{~g} / \mathrm{mol}$ molar mass depending on the variant and a net negative charge at pH 6-9 (-1 for MC-LR, -2 for the other variants). Microcystins were extracted from M. aeruginosa culture following Meriluoto and Spoof's procedure with the adaptations described by Campinas and Rosa [16].

\subsection{Characterisation of cultures growth phases}

This study required a previous characterisation of $M$. aeruginosa cultures harvested at different growth ages, in order to tackle the main objective of this paper, which was to evaluate the cyanobacterial cells retention and integrity during ultrafiltration and the effect of cell age (cell vulnerability and AOM content) onto the UF performance.

Cyanotoxins are produced at all stages of cyanobacterial growth and generally remain in the cell (intracellular) until age or stressdriven cell lysis causes their release into the surrounding water (extracellular) [4]. During the growth phases, together with the variation in the cyanobacterial biomass, strong changes occur in the AOM production, in the total cyanotoxin content, and in the intra/extracellular cyanotoxin ratio.

Pivokonsky et al. [17] showed that the amount of AOM produced by $M$. aeruginosa culture increased with ageing and the proportion of proteic organic matter also increased, reaching about $31 \%$ of DOC in the stationary phase. A significantly greater portion of proteins was in the IOM (intracellular organic matter) fraction, while the EOM (extracellular organic matter) fraction was mainly composed of organics with no proteic character (e.g. polysaccharides). The organic matter content and the contribution of IOM to the total AOM concentration both increased during the stationary phase due to autolytic processes.

In general, intracellular microcystins are produced during the exponential-growth phase. Further generation happens during the stationary phase and a sharp rise of dissolved microcystins occurs during decaying algae growth phase [6]. Pietsch et al. [6] found that a $M$. aeruginosa sample was characterised by an extra/intra MC-LR ratio of 0.05 in the exponential phase and by a ratio of 1 (extra equals intracellular contribution) in the stationary phase.

To understand the growth phases of the $M$. aeruginosa cultures used in this study, five cultures of different ages (1-6 months old)
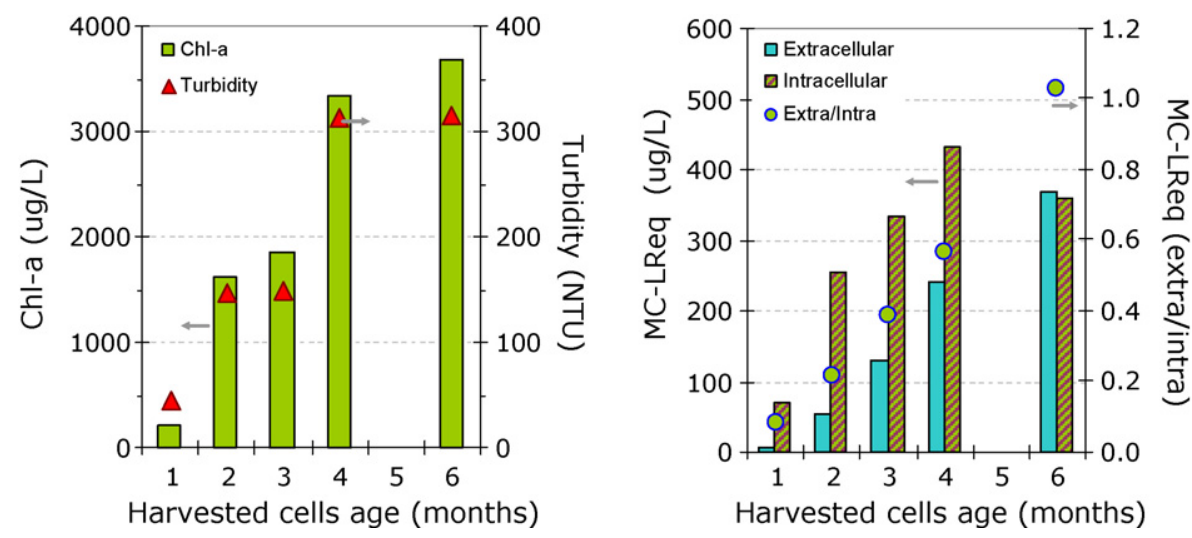

Fig. 1. Characterisation of the growth phases of the studied M. aeruginosa cultures. 
Table 1

Characteristics of $M$. aeruginosa suspensions used in the UF experiments.

\begin{tabular}{|c|c|c|c|c|c|c|c|c|}
\hline \multirow[t]{2}{*}{ Suspensions } & \multirow[t]{2}{*}{ UF experiment } & \multirow[t]{2}{*}{$\mathrm{pH}$} & \multirow[t]{2}{*}{$\mathrm{EC}(\mu \mathrm{S} / \mathrm{cm})$} & \multirow[t]{2}{*}{ Turbidity (NTU) } & \multirow[t]{2}{*}{ Chl-a ( $\mu \mathrm{g} / \mathrm{L})$} & \multirow[t]{2}{*}{$\mathrm{TOC}(\mathrm{mg} \mathrm{C} / \mathrm{L})$} & \multicolumn{2}{|c|}{ MC-LR eq $(\mu \mathrm{g} / \mathrm{L})$} \\
\hline & & & & & & & Extra & Intra \\
\hline \multirow{2}{*}{1 month old } & Constant TMP & 7.3 & 301 & 4.5 & 17.4 & 3.3 & 9.7 & - \\
\hline & Constant flow & 7.2 & 310 & 5.3 & 28.0 & 2.2 & 8.9 & - \\
\hline 2 months old & Constant flow & 6.7 & 293 & 2.5 & 20.6 & - & 0.6 & 1.5 \\
\hline \multirow{2}{*}{3 months old } & Constant TMP & 6.7 & 256 & 2.8 & 17.4 & 2.1 & 1.4 & - \\
\hline & Constant flow & 7.3 & 294 & 3.4 & 20.0 & 3.4 & 2.9 & - \\
\hline 4 months old & Constant Flow & 6.7 & 301 & 2.8 & 19.2 & - & 0.5 & 2.1 \\
\hline
\end{tabular}

TMP: transmembrane pressure; EC: electrical conductivity; Chl-a: chlorophyll-a.

were characterised in terms of chlorophyll-a, turbidity, extra and intracellular microcystin concentrations and extra/intra MC-LReq ratio (Fig. 1).

Fig. 1 shows that all parameters have three increasing stages. After 1 month, chlorophyll-a was $211 \mu \mathrm{g} / \mathrm{L}$, increasing to $1622-1857 \mu \mathrm{g} / \mathrm{L}$ in $2-3$ months and finally to $3331-3687 \mu \mathrm{g} / \mathrm{L}$ in 4-6 months. Turbidity had the same pattern, increasing from 45 NTU (1 month) to 147-150 NTU (2-3 months) and afterwards to 312-314 NTU (4-6 months). Total microcystin concentration also augmented from $74.3 \mu \mathrm{g} / \mathrm{L}$ MC-LReq $(1$ month) to $308-461 \mu \mathrm{g} / \mathrm{L}$ (2-3 months) and finally to $673-725 \mu \mathrm{g} / \mathrm{L}$ (4-6 months). In all samples, the extra/intracellular microcystin ratio increased with ageing and presented the minimum value of 0.08 for the 1 -month-old culture and the maximum value of 1 for the 6 -month-old culture. These results indicate that a culture 1-month old corresponds to exponential phase, 2-3 months old to late-exponential phase, and 4 months old to stationary phase.

\subsection{UF feed waters}

Preliminary UF runs performed to assess the microcystin adsorption to the UF membrane used single-solute model solutions of $12.3-13.7 \mu \mathrm{g} / \mathrm{L}$ MC-LR $\mathrm{eq}_{\mathrm{eq}}$ dissolved in a background electrolyte $2.5 \mathrm{mM}$ ionic strength (IS) ( $1 \mathrm{mM}$ IS of $\mathrm{KCl}$ and $1.5 \mathrm{mM}$ IS of $\mathrm{CaCl}_{2}$ ), pH $7.0 \pm 0.3$ (adjusted with $\mathrm{KOH}$ and $\mathrm{H}_{2} \mathrm{SO}_{4}$ ).

$M$. aeruginosa suspensions used in the UF experiments were prepared by spiking a background electrolyte with a predetermined volume of $M$. aeruginosa culture to obtain a chlorophyll-a (chl-a) concentration of ca. $20 \mu \mathrm{g} / \mathrm{L}$ (Table 1 ). This specific concentration is less than half the WHO Alert Level 2 established by Bartram et al. [18] for a potentially toxic cyanobacterial bloom (cyanobacterial biomass 100,000 cells/mL or $50 \mu \mathrm{g} / \mathrm{L}$ chl-a) and aims to simulate a weak bloom and/or a strong bloom after preliminary treatment. Cultures harvested at different growth ages (1, 2, 3 and 4 months old) were used to test different cell vulnerabilities. To avoid osmotic shock which may result in cyanobacterial cell lysis, the cells were spiked in a background electrolyte prepared with deionised water amended with potassium chloride until the water conductivity reached ca. $260 \mu \mathrm{S} / \mathrm{cm}$. The $\mathrm{pH}$ was also corrected to $7.0 \pm 0.3$ with $\mathrm{KOH}$ and $\mathrm{H}_{2} \mathrm{SO}_{4}$.

\subsection{Membrane}

An Aquasource cellulose acetate hollow-fibre (inside-out configuration) membrane was used. This UF hydrophilic membrane has a molar mass cut-off of $100 \mathrm{kDa}$ and a hydraulic permeability of $250 \mathrm{~L} /\left(\mathrm{h} \mathrm{m}^{2}\right.$ bar) (manufacturer data). The module has 16 fibres (1.1 m length and $0.93 \mathrm{~mm}$ internal diameter) with a total surface area of $0.05 \mathrm{~m}^{2}$. The manufacturer recommends a maximum UF pressure of 1.5 bar and a maximum backflushing pressure of 2.5 bar.

\subsection{Ultrafiltration experiments}

UF experiments were all performed in cross-flow filtration mode, i.e. the feed streams flowed tangentially to the membrane surface and originated two different streams, the concentrate (containing the compounds unable to cross the membrane pores) which was recirculated and mixed with the incoming feed stream, and the permeate (treated water). Prior to its first use and before each UF experiment, the membrane was washed, flushed and compacted with deionised water until achieving a steady pure water permeate flux, at the pressure and cross-flow velocity values to be used in the experiments. Two types of UF experiments were performed: (i) constant flow runs resembling the operation of industrial UF plants and (ii) concentration runs at constant transmembrane pressure (TMP) to evaluate the effect of the initial concentration on the membrane performance.

A schematic diagram of the UF lab-scale unit is provided in Fig. 2 (dotted lines represent the adaptations made for constant flow runs).

The first type of runs (Constant flow, Table 1) were performed at constant permeate flow of $3.5 \mathrm{~L} / \mathrm{h}$ and initial transmembrane pressure of 0.65 bar. A feed glass tank (FT) fed the raw water to the recirculating tank (RT) through a peristaltic pump at a constant flow of $3.5 \mathrm{~L} / \mathrm{h}$ to balance the permeate outflow. The positive displacement pump provided the necessary pressure and the cross-flow velocity of $0.5 \mathrm{~m} / \mathrm{s}$ (a variable-frequency drive allowed the velocity in the hollow-fibres to be adjusted). The concentrate was conducted to RT and blended with the additional feed water from FT, whereas the permeate was continuously collected in a beaker until a 1-L sample was obtained. By that time, RT was sampled $(200 \mathrm{~mL})$ to characterise the UF feed water. Filtration cycles lasted $60 \mathrm{~min}$, i.e. four samples of permeate were always collected: three samples of 1 L each (0-17 $\mathrm{min}, 17-34 \mathrm{~min}, 34-51 \mathrm{~min})$ and the last one with $\mathrm{ca}$. $0.5 \mathrm{~L}$ (51-60 min). Individual concentrations were determined and whenever necessary for data interpretation cycle-averaged values (0-60 min) were computed. After each filtration run the membranes were washed with a $5-\mathrm{mg} / \mathrm{L}\left(\right.$ as $\mathrm{Cl}_{2}$ ) sodium hypochlorite solution to inhibit the biological activity on the UF system, and thoroughly flushed with deionised water.

Concentration runs (Constant TMP, Table 1) were performed at a constant TMP of 0.6 bar, with a positive displacement pump feeding the raw water (predefined volumes) to the UF membrane. In this set of runs, RT served as both the feed and the recirculating tank, i.e. neither FT nor the peristaltic pump were used. The concentrate was recycled to $\mathrm{RT}$ and the permeate was continuously measured in PT and discarded. Thereby, during the concentration runs the water recovery rate (WRR, defined as the ratio between the permeate volume collected so far and the initial feed volume) was continuously increasing. At given predefined WRR values (66\%, 90\%, and for comparison purposes $0 \%$, i.e. before starting to discarding the permeate) the permeate was exceptionally recycled to the feed tank for 5 min to equilibrate concentrations, after which $250 \mathrm{~mL}$ samples of the feed and permeate were taken. 


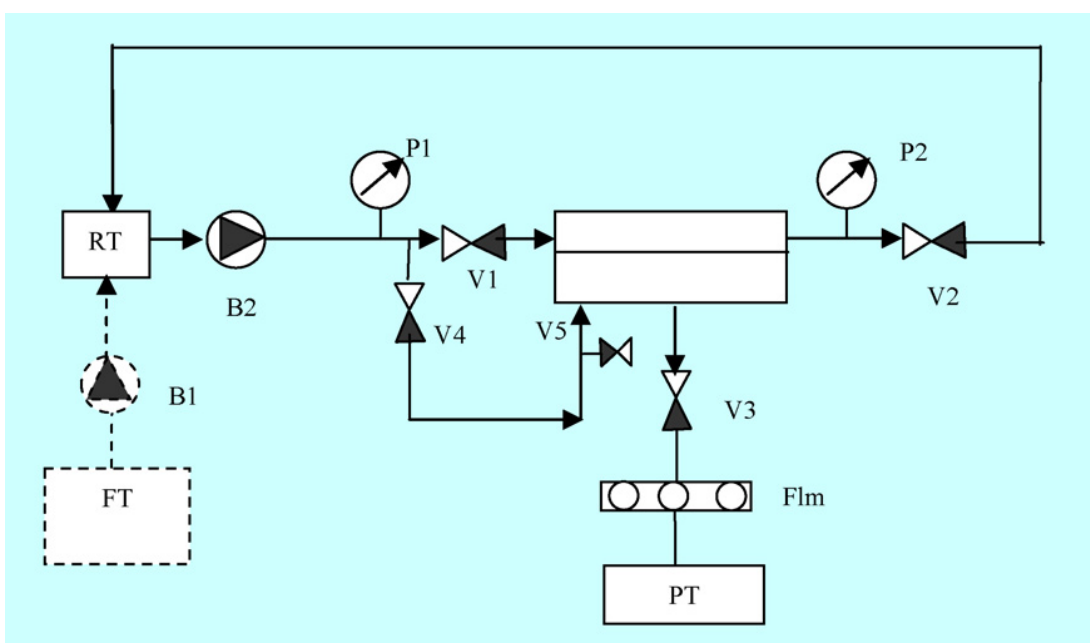

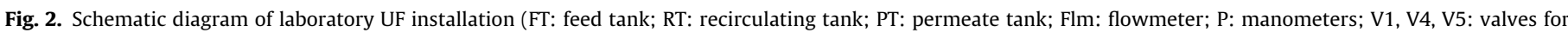
backwashing; V2: concentrate valve; V3: permeate valve; B1: peristaltic pump; B2: positive displacement pump).

Permeate flux was continuously measured during the experiments and normalised fluxes were computed from the ratio of solution flux over the pure water flux measured before each run. Fluxes were all corrected to a constant temperature $\left(20^{\circ} \mathrm{C}\right)$ using the equation derived by Crozes et al. [19], which is based on the variation of water viscosity with temperature:

$J_{20}=J_{T} e^{-0.0239(T-20)}$

where $J_{20}$ is the flux $\left(\mathrm{L} /\left(\min \mathrm{m}^{2}\right)\right)$ at $20^{\circ} \mathrm{C}, T$ is the temperature $\left({ }^{\circ} \mathrm{C}\right)$ and $J_{T}\left(\mathrm{~L} /\left(\min \mathrm{m}^{2}\right)\right)$ is the flux at temperature $T$.

\subsection{Analytical methods}

Samples were analysed for $\mathrm{pH}$ (at $20^{\circ} \mathrm{C}$, using a WTW 340 $\mathrm{pH}$ meter), electrical conductivity (EC) (at $25^{\circ} \mathrm{C}$, using a Crison GLP 32 conductimeter), total organic carbon (TOC) (measured as non-purgable organic carbon in a high temperature combustion Shimadzu 5000A carbon analyser) and turbidity (HACH 2100N turbidimeter of high resolution, 0.001 NTU) using standard methods for water analysis. For chlorophyll-a, $100-200 \mathrm{~mL}$ (feed) or $1 \mathrm{~L}$ (permeate) samples were filtered through GF/F filter paper and the chlorophylls were extracted using $10 \mathrm{~mL}$ acetone (90\%). The optical densities of the extracts were measured at $665 \mathrm{~nm}$ and $750 \mathrm{~nm}$ using a Beckman DU 640B UV/vis spectrophotometer and chl-a concentration was computed from Lorenzen equations [20].

In the first experiments using the $M$. aeruginosa suspensions 1 month and 3 months old only dissolved microcystins were determined in the feed samples $(200 \mathrm{~mL})$, whereas in the last experiments using the 2 and the 4-month-old suspensions both cell-bound (in $100 \mathrm{~mL}$ samples) and dissolved microcystins (in $200 \mathrm{~mL}$ samples) were analysed. As for permeate samples, only extracellular microcystins were analysed in $1000 \mathrm{~mL}$ samples in constant flow experiments and in $200 \mathrm{~mL}$ samples in concentration runs.

Microcystin analysis followed the standard operation procedures developed by Meriluoto and Spoof [21-23] with some adaptations. Extracellular microcystins were first isolated from cell-bound microcystins by sample filtration through a Whatman GF/C glass microfibre filter. The dissolved fraction was then concentrated by solid-phase extraction in isolute C18 cartridges and the microcystins were eluted with $5 \mathrm{~mL}$ methanol (90\%) containing $0.1 \%(\mathrm{v} / \mathrm{v})$ trifluoracetic acid (further details in Ribau Teixeira and Rosa [10]). For intracellular microcystins, the filters were freezethawed twice and kept in methanol $(75 \%, v / v)$ during $18-24 \mathrm{~h}$ at $4{ }^{\circ} \mathrm{C}$. The methanolic extracts of extracellular toxins and of cell-bound toxins were rotary evaporated at $50^{\circ} \mathrm{C}$, resuspended in $500 \mu \mathrm{L}$ methanol $(75 \%)$, centrifuged $(10,000 \times g, 10 \mathrm{~min})$ and $150 \mu \mathrm{L}$ of the supernatant were transferred to HPLC vials for analysis. Microcystins were analysed by high-performance liquid chromatography with photodiode-array detection (HPLC-PDA), using a Dionex Summit System. The four microcystin variants produced by $M$. aeruginosa and identified by HPLC analysis (MC-LR, -LY, -LW, -LF) were all quantified as $\mu \mathrm{g} / \mathrm{L}$ MC-LR (MC-LR eq $)$ using a pure MC-LR standard. The microcystin concentration presented in the following sections is always the overall concentration computed from the sum of the four variants and is therefore presented as $\mu \mathrm{g} / \mathrm{L}$ MC-LReq.

\section{Results and discussion}

\subsection{Retention of cyanobacterial cells}

In this study, chlorophyll-a was used to assess the overall removal efficiency of cyanobacterial cells. Since a relation between chlorophyll-a and turbidity was observed for M. aeruginosa laboratory grown cultures (10-11 $\mu \mathrm{g} / \mathrm{L}$ chl-a corresponding to $\mathrm{ca}$. $1 \mathrm{NTU}$ ), turbidity results were also used for such purpose. Fig. 3 presents the turbidity and chl-a feed profiles (Fig. 3, left) and the cycle-averaged concentrations in the feed and permeate (Fig. 3, right) during the constant flow UF cycles performed with $M$. aeruginosa cells 2 and 4 months old) (the error bars represent the standard deviations).

Although during the filtration cycle of both culture suspensions turbidity and chl-a concentration have increased in the feed, respectively from $2.4-2.7$ NTU to $3.3-3.5$ NTU and $19-21 \mu \mathrm{g} / \mathrm{L}$ to $36 \mu \mathrm{g} / \mathrm{L}$, the quality of the permeate was always high. Turbidity was kept below $0.1 \mathrm{NTU}$ (except in one sample) corresponding to rejections above $97 \%$ and chlorophyll-a was never detected in the permeate (complete rejection). Similar results were obtained in the experiments performed with cells 1 and 3 months old (data not shown). The results indicate an absolute removal of $M$. aeruginosa cells, as expected since they are 400-600 times larger than the membrane pores (single cells diameter is about 4-6 $\mu \mathrm{m}$ and the membrane cut-off is $100 \mathrm{kDa}$, which corresponds to an average pore diameter of ca. $0.01 \mu \mathrm{m}[12])$.

Ultrafiltration results of cell retention are comparable and usually substantially better than the removal achieved by a conventional treatment of coagulation/flocculation and sedimentation or DAF (C/F/S or $\mathrm{C} / \mathrm{F} / \mathrm{DAF}$, respectively) and filtration (F). Vlaski et al. [24] obtained algae removals of $90 \%$ by $C / F / D A F / F$ and $95 \%$ by 

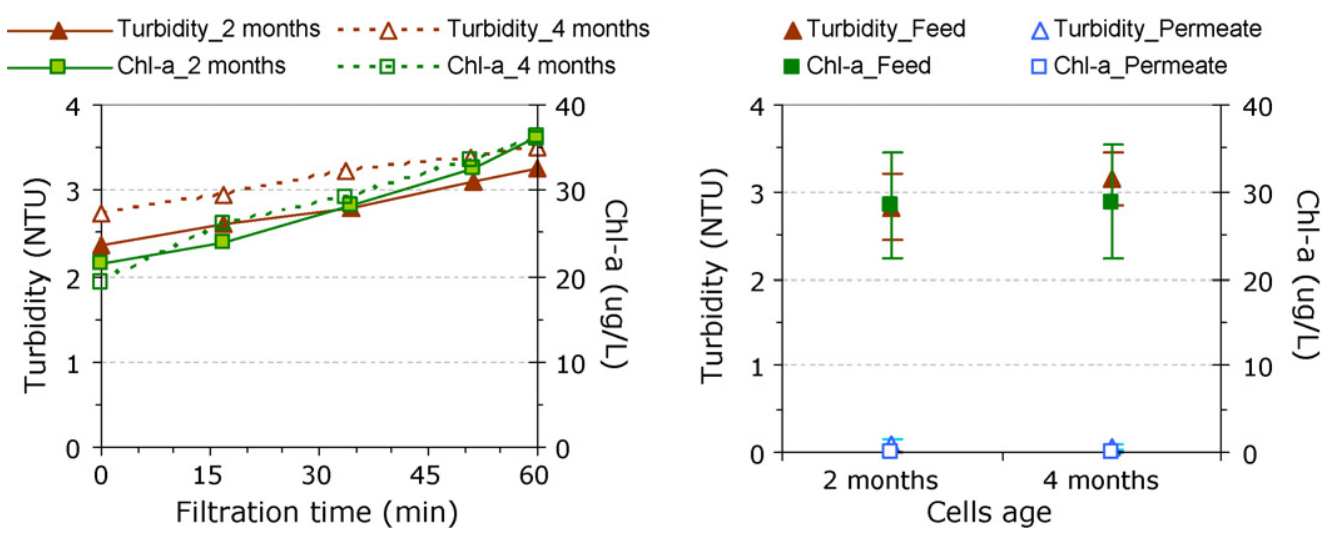

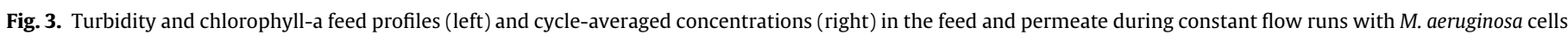
2 and 4 months old.

C/F/S/F, whereas Ribau Teixeira and Rosa $[10,11]$ reported $M$. aeruginosa cells retentions of $69-94 \%$ by $\mathrm{C} / \mathrm{F} / \mathrm{S}$ and $77-99 \%$ by $\mathrm{C} / \mathrm{F} / \mathrm{DAF}$.

As single cells are the lowest size cyanobacteria (and must therefore be the most difficult to retain by a solid-liquid separation) and are Giardia cysts and Cryptosporidium oocysts surrogates [24], these results confirm that UF is a safe barrier against cyanobacteria and protozoa, as reported in the literature [25]. This is a very important feature due to the chemical resistance to oxidation exhibited by the Giardia cysts and the Cryptosporidium oocysts.

\subsection{Cell lysis and release of microcystins to water}

Cyanobacterial cells integrity during ultrafiltration is a key issue since the shear stresses developed at the membrane surface or from pumping may cause cell damage, with subsequent release of intracellular cyanotoxins and IOM into the permeate.

Rather than investigating the cell lysis phenomenon per se, which would require direct cell lysis analysis, this paper addresses the effect of cell lysis on the permeate quality. Provided no rejection or adsorption of the extracellular microcystin by the UF cellulose acetate membrane occurs, the easiest way to indirectly assess cell lysis is to follow the evolution of the dissolved microcystin concentration in the feed and permeate during the filtration cycle.

Preliminary experiments with model single-solute solutions of microcystins were therefore designed to evaluate if the UF cellulose acetate membrane was able to reject microcystins and if microcystins exhibited a membrane fouling behaviour. Low-molar mass solutes may cause drastic flux reductions during UF due to adsorption, and the solute concentration and membrane material have an important influence on the membrane fouling potential [26].
The studied microcystins are relatively hydrophobic compounds with a molar mass (985-1024 Da) much below the cut-off of the hydrophilic membrane ( $100 \mathrm{kDa})$, making rejection through sieving not an option, but probably through adsorption.

A concentration run and a constant flow run were performed. Fig. 4 presents the normalised flux (Fig. 4, left) and the rejection of microcystins (Fig. 4, right) as a function of WRR during the UF concentration run of the microcystin model solution, whereas Fig. 5 presents the cycle-averaged concentration of microcystins in the feed and permeate during the constant flow UF cycle with the same model solution (the error bars represent the standard deviations).

Normalised flux is very similar in the presence and in the absence of microcystins for WRR up to $60 \%$, corresponding to 52 min of operation (Fig. 4, left). Above $60 \%$, microcystins seem to slightly promote the flux decline ( $\mathrm{ca} .10 \%$ maximum), probably due to increased adsorption of microcystins onto the membrane surface. In fact, the initially negligible (2\%) microcystin rejection slightly increased up to $11 \%$ for $90 \%$ WRR and 110 min of operation (Fig. 4, right). A strong foulant behaviour of microcystins was also observed by Ribau Teixeira and Rosa [27] with a hydrophilic NF membrane and a feed concentration of $150 \mu \mathrm{g} / \mathrm{L}$ MC-LR eq whereas a largely attenuated fouling was observed with $16 \mu \mathrm{g} / \mathrm{L}$ MC-LR feed water.

During the constant flow experiment no significant pressure changes were observed (and these data are therefore not shown) and the cycle-averaged concentrations of microcystins in the feed and permeate are quite similar (4\% average rejection, Fig. 5 ). These results indicate a low adsorption under the studied conditions and are not far from those obtained by Lee and Walker [28] with a cellulose acetate flat-sheet UF membrane $(0.9 \%$ of rejec-
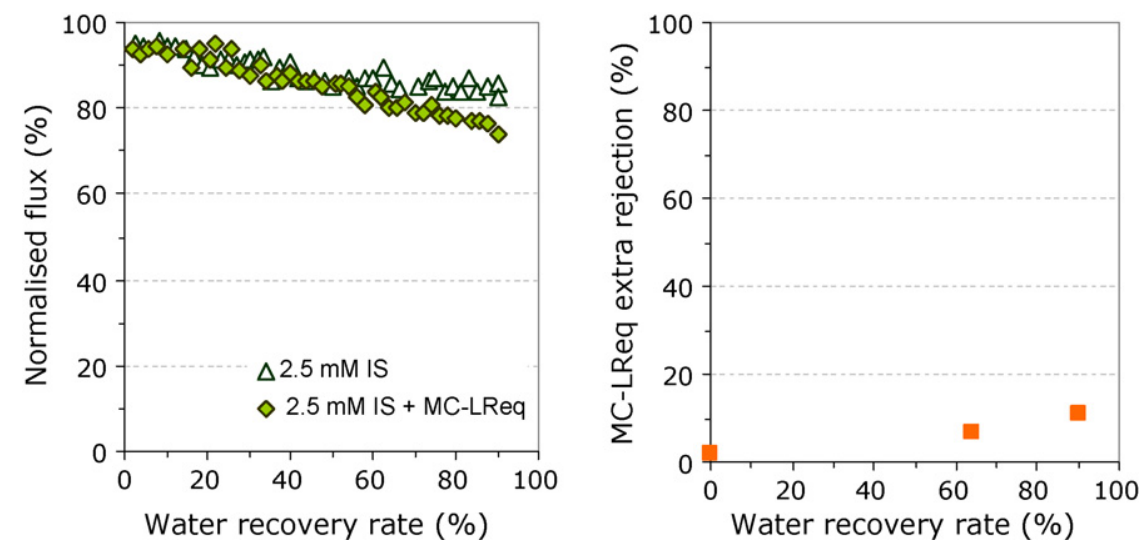

Fig. 4. Normalised flux (left) and dissolved microcystin rejection (right) during UF concentration runs with single-solute model solution. 


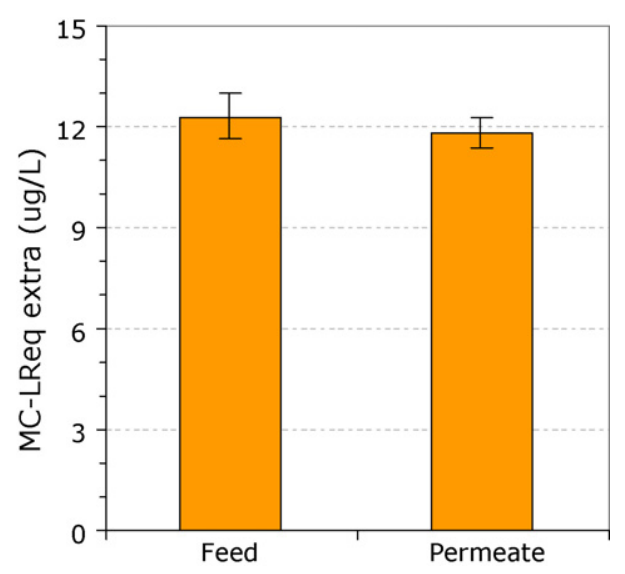

Fig. 5. Cycle-averaged concentration of dissolved microcystins in the feed and permeate during constant flow runs with single-solute model solution.

tion). Higher rejections of microcystins were reported by others for hydrophobic membranes due to adsorption phenomena. Using polyethersulphone membranes, Lee and Walker [28] obtained 67-78\% adsorption and Gijsbertsen-Abrahamse et al. [14] referred a $53 \%$ rejection. The polysulphone membrane used by Chow et al. [12] also exhibited rejection properties for microcystins, particularly in the cross-flow run (ca. 23\%).

Given these preliminary results, a first set of experiments was performed with $M$. aeruginosa cultures 1 and 3 months old, and the dissolved microcystin concentration was monitored in the feed and in the permeate. Fig. 6 shows a cycle-averaged rejection of microcystins of $33 \%$ with 1-month-old cells and $65 \%$ with 3 -month-old cells. The most probable explanation for the microcystin rejection exhibited by both cultures is the AOM-microcystins interaction, which confers rejection properties to the hydrophilic membrane.

One remark has to be made with respect to the higher concentration of dissolved microcystins in the 1-month-old culture than in the 3-month-old culture (Fig. 6). Since older cultures have in general higher microcystin content this is an unrealistic scenario explained by the larger spiking volume of the 1-month-old culture used to obtain identical chlorophyll-a concentration in both cultures.

Due to the existence of AOM-driven adsorption of microcystins, cell lysis evaluation based only on the time evolution of the dissolved microcystins concentration in the feed and permeate is not valid and underestimates the cell lysis phenomenon. As cell lysis and microcystin adsorption may happen simultaneously and can-

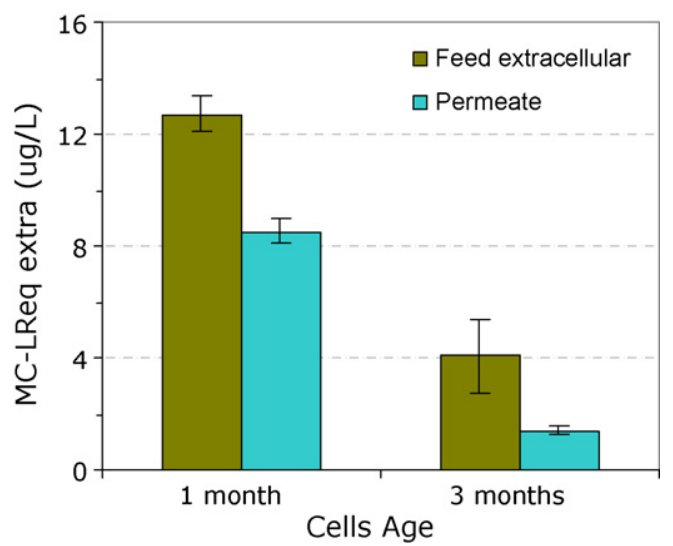

Fig. 6. Cycle-averaged concentration of dissolved microcystins in the feed and permeate during constant flow runs with $M$. aeruginosa cells 1 and 3 months old (the error bars represent standard deviations).

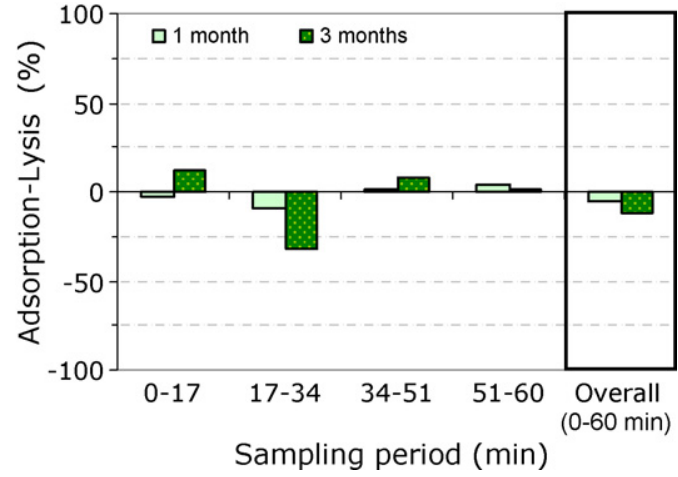

Fig. 7. Net contribution of adsorption and cell lysis computed from mass-balance equation developed for dissolved microcystins during constant flow UF cycles with M. aeruginosa cells 1 and 3 months old.

not be differentiated, their net contribution was computed from mass-balance derived for dissolved microcystins.

Mass-balance equation considered three inputs (the initial mass in RT, the feed input and the input from cell lysis) and three outputs (the final mass in RT, the permeate output and the adsorption). The difference between adsorption and lysis was normalised as expressed in the following equation:

$\%($ Ads - Lysis $)=\frac{\left(V_{0} C_{0}+Q t C-V_{f} C_{f}-\sum_{i=1}^{4} Q_{p i} t_{i} C_{p i}\right)}{\left(V_{0} C_{0}+Q t C-\sum_{i=1}^{4} Q_{p i} t_{i} C_{p i}\right)} \times 100$

where $V_{0}$ and $C_{0}$ are the initial volume (L) and concentration $(\mu \mathrm{g} / \mathrm{L})$ in RT, respectively; $Q$ is the feed flow $(\mathrm{L} / \mathrm{min}$ ) (make-up to balance the permeate outflow), $t$ and $C$ are the associated feed pumping time ( $\mathrm{min}$ ) and concentration $(\mu \mathrm{g} / \mathrm{L}) ; V_{f}$ and $C_{f}$ are the final volume $(\mathrm{L})$ and concentration $(\mu \mathrm{g} / \mathrm{L})$ in RT; $Q_{p i}, t_{i}$ and $C_{p i}$ are the permeate flow ( $\mathrm{L} / \mathrm{min})$, pumping time ( $\mathrm{min})$ and concentration $(\mu \mathrm{g} / \mathrm{L})$.

The net contribution of adsorption and cell lysis computed for dissolved microcystin concentration during the constant flow UF cycles with $M$. aeruginosa cells 1 and 3 months old is depicted on Fig. 7. During these cycles there were some periods when cell lysis exceeded the adsorption (negative bars) and others when adsorption was more important (positive bars), but the overall net balance for both cultures indicated the cell lysis dominance over the adsorption, with greater expression for the cells 3 months old. Nevertheless, the cell damage did not compromise the permeate quality since the microcystin concentration in permeate was always below its concentration in the feed (Fig. 6).

The experiments were repeated 1 month latter with the same cultures, i.e. by the time of the second set of trials the cultures were 2 and 4 months old. Given the difficult interpretation of the dissolved microcystin results, cell lysis was further assessed through the evolution of the intra-microcystin and chlorophyll-a contents in the feed during the filtration cycle. Results were analysed through concentration factors $\left(C f=C / C_{0}\right)$ for those two parameters, comparing the experimental $C f$ values with the expected ones. The latter were computed by mass-balance equation assuming complete rejection, no adsorption and no cell lysis. Experimental $C f$ values lower than expected $C f$ values were therefore interpreted as cell lysis (Fig. 8).

Fig. 8 (left) confirms the cell lysis occurrence in both cultures, although with greater significance in the older culture and at the end of the filtration cycle. Chlorophyll-a concentration (Fig. 8, right) is less sensitive to cell lysis than the concentration of intra-microcystins. This finding suggests the intra-microcystin/chl- 

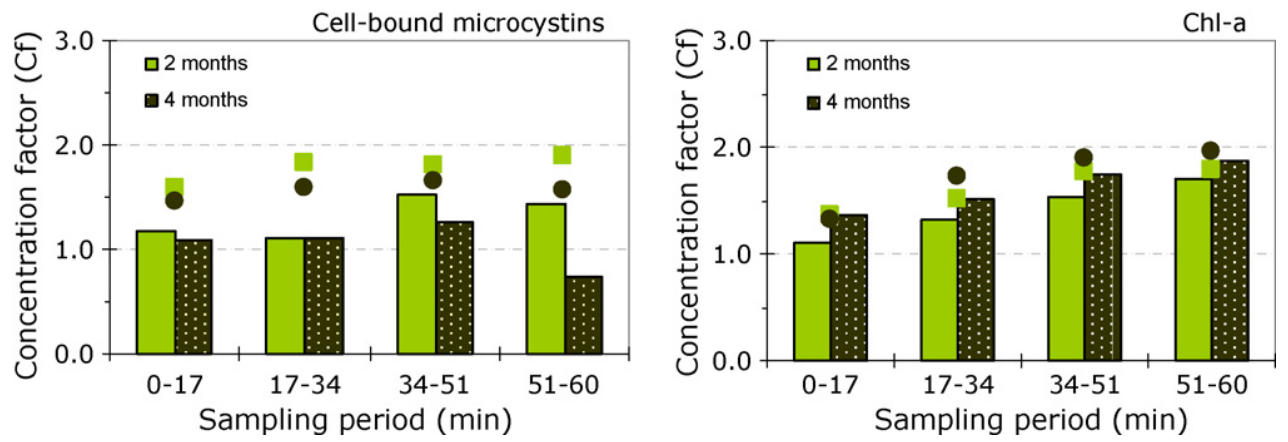

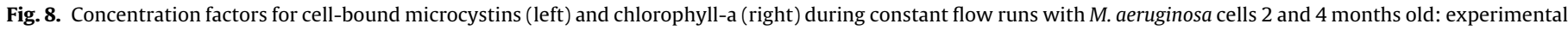
(bars) and expected (symbols) values based on mass-balance equation.

a ratio as an indirect measure of cell lysis; further experiments are however necessary to confirm this hypothesis.

Fig. 9 presents the net contribution of adsorption and cell lysis computed for dissolved microcystin concentration during the experiments with the cell suspensions 2 and 4 months old.

The overall net contribution indicated again a dominance of cell lysis over the adsorption for both cultures. The more significant cell lysis observed for the cells 4 months old, so clearly expressed in Fig. 8 (left), was not evident in Fig. 9, which indicates the importance of the adsorption phenomenon for this older culture. In parallel to cell damage, an enhancement of microcystin rejection by the UF cellulose acetate membrane must occur with ageing, probably associated with the greater content in segregated AOM (mucopolysaccharides) and/or protein lysed AOM of older cultures. For that matter, the permeate quality did not degrade, neither with the youngest nor even with the oldest culture tested (Fig. 10). Microcystin concentration in the permeate was similar or lower than its feed concentration, with cycle-averaged rejections of total (extra + intra) microcystins of $60 \%$ using the 2 -month-old culture and $80 \%$ with the 4 -month-old cells.

It can be therefore concluded that cell lysis occurred during the UF runs, especially for older cultures, but this phenomenon did not result in a net degradation of the permeate quality since in parallel to cell damage an enhancement of microcystin rejection by the UF cellulose acetate membrane was observed with ageing, probably due to AOM-driven microcystin adsorption on the membrane. Pietsch et al. [6] obtained also higher cell removals and cell lysis by flocculation of $M$. aeruginosa in the stationary-growth phase than with cells in the exponential growth phase.

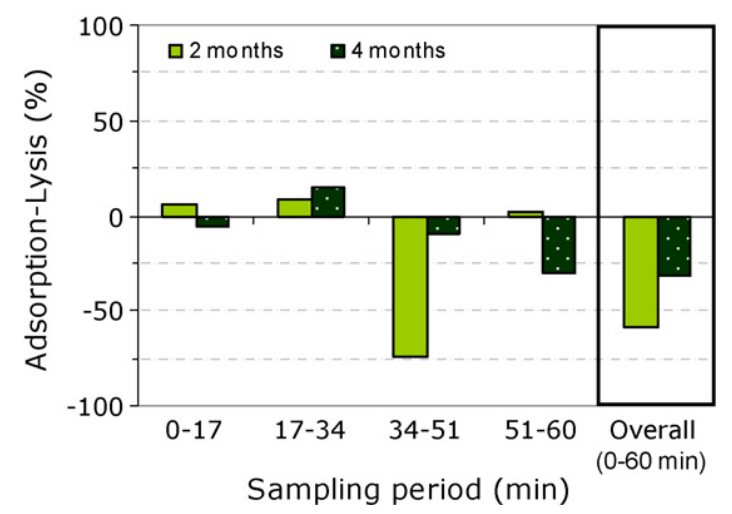

Fig. 9. Net contribution of adsorption and cell lysis computed from mass-balance equation developed for dissolved microcystins during constant flow UF cycles with M. aeruginosa cells 2 and 4 months old.

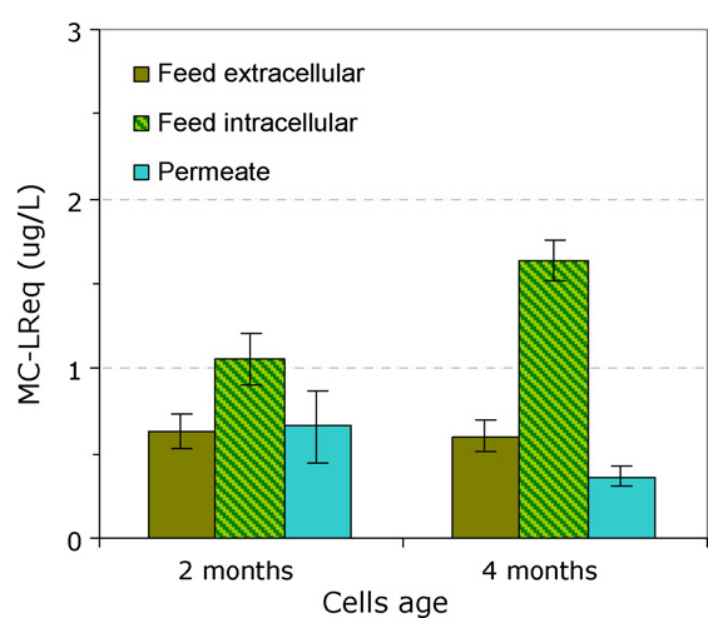

Fig. 10. Cycle-averaged concentration of microcystins (extra and intracellular) in the feed and permeate during constant flow runs with $M$. aeruginosa cells 2 and 4 months old (the error bars represent standard deviations).

\subsection{Membrane fouling by AOM}

The distinct behaviour observed for microcystin rejection by the cellulose acetate UF membrane in the absence and in the presence of cyanobacterial culture (Fig. 5 right vs. Fig. 6; Fig. 4 right vs. Fig. 12, bottom-right) is probably due to the AOM segregated during the metabolic activity (EOM) or resulting from cells decaying (IOM). These organic substances include a wide range of compounds, such as oligo and polysaccharides, proteins, peptides, amino acids and also traces of other organic acids [17]. Many polysaccharides have

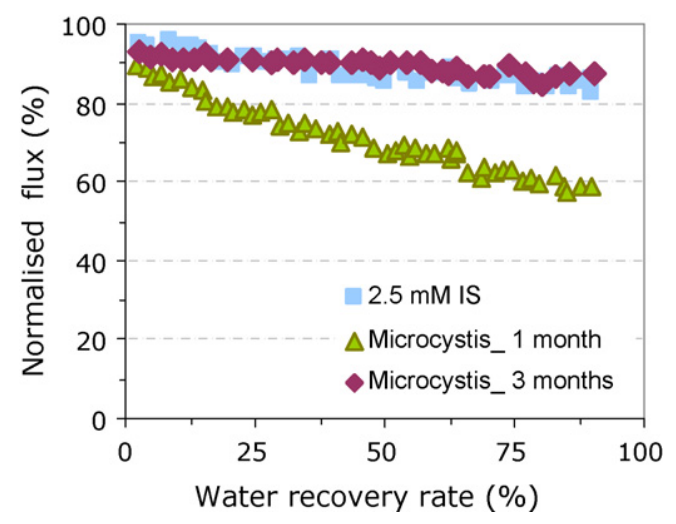

Fig. 11. Normalised flux during UF concentration runs with $M$. aeruginosa cells 1 and 3 months old. 

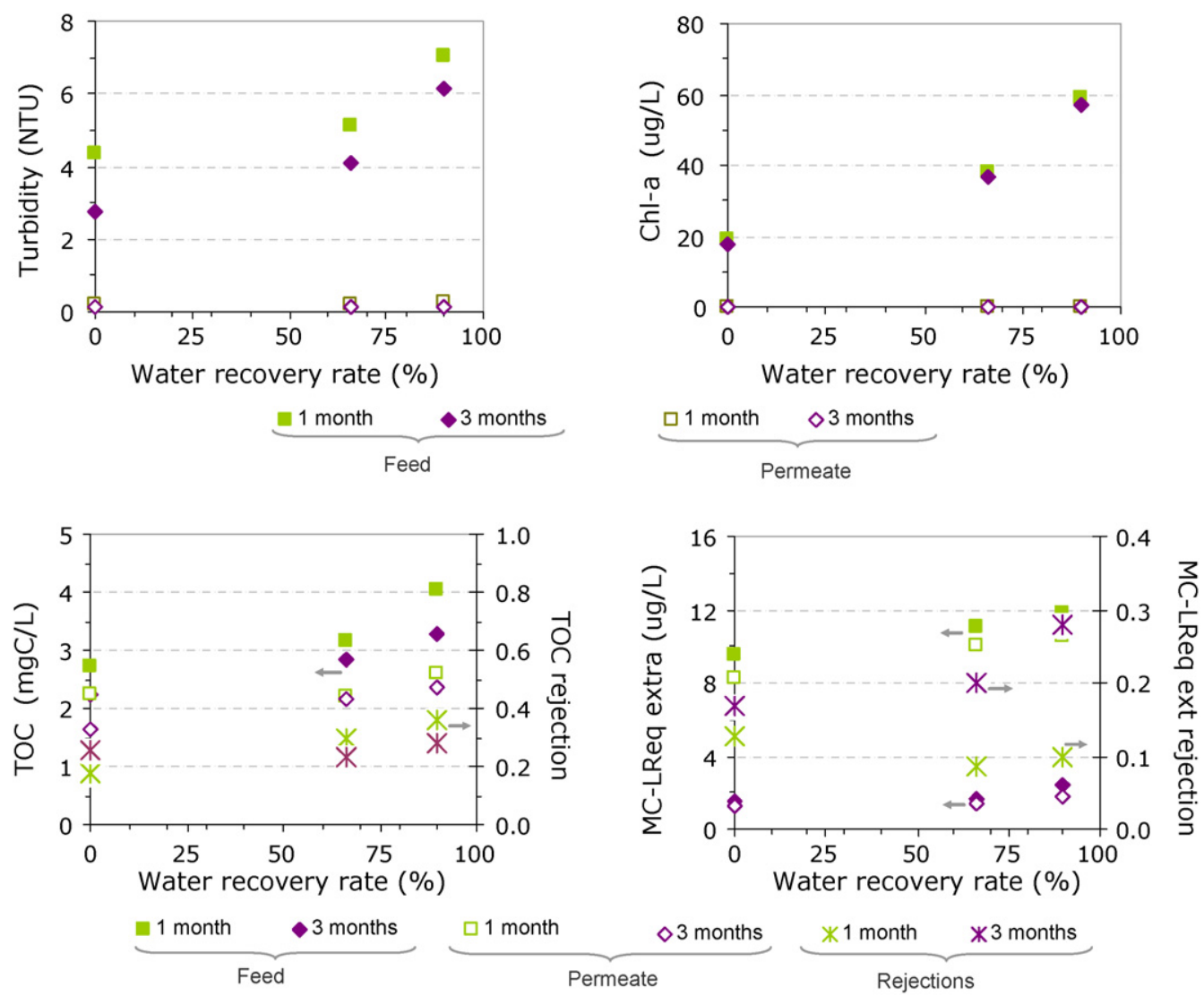

Fig. 12. Feed (closed symbols) and permeate (open symbols) quality, and rejections (asterisks) during UF concentration runs with $M$. aeruginosa cells 1 and 3 months old

inherent "stickness" and capacity for adsorption of other chemicals or particles and may act as thickening agents or bioflocculants [29], which explains the enhancement of microcystin rejection in the presence of AOM. Aggregation or enmeshment of dissolved microcystins onto organic matter could result in its physical exclusion by the membrane or in stronger adsorption onto the membrane surface. These polysaccharides and proteins were also found to be responsible for significant membrane fouling [30,31].

The results of normalised flux $v s$. WRR obtained in the UF concentration experiments with $M$. aeruginosa cells 1 and 3 months old are presented in Fig. 11. Fig. 12 shows the feed and permeate quality (turbidity, chlorophyll-a, TOC and microcystin concentrations), as well as TOC and microcystin rejections.

With the 1-month-old culture, the flux decline with WRR was very severe (normalised flux was $60 \%$ for $90 \%$ WRR), whereas for the 3-month-old culture no significant flux decline was observed (Fig. 11). However, the overall quality of both suspensions was quite similar (17.4 $\mu \mathrm{g} / \mathrm{L}$ chl-a in both suspensions; $4.5 \mathrm{NTU}$ (1 month) $v$ s. 2.8 NTU (3 months); 3.3 vs. 2.1 mgC/L TOC; pH 7.3 vs. 6.7; 301 vs. 256

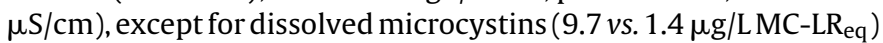
and kept similar during the run in both the feed and the permeate. Therefore, the type rather than the overall concentration of salts and organics must explain the distinct membrane fouling observed. As previously referred, a larger spiking volume was used to prepare the 1-month-old suspension (almost 6 times the volume used for the 3-month-old suspension), which means that the 1-month-old suspension had greater contribution of the dissolved microcystins and polysaccharide-type AOM, as well as of the growth medium ions (yielding a conductivity of $190 \mu \mathrm{S} / \mathrm{cm}$ for the suspension 1 month old $v$ s. $28 \mu \mathrm{S} / \mathrm{cm}$ for the 3-month-old suspension, values further adjusted to $260-300 \mu \mathrm{S} / \mathrm{cm}$ prior to the UF runs). These mono and multivalent ions may be responsible for NOM aggregation and precipitation, causing membrane fouling.
By other side, the assayed water containing the culture 3 months old, given the cell age and cell decaying vulnerability, probably had higher proportion of proteic organic matter compared to the assayed water with the cells 1 month old, whose AOM must predominantly consist of polysaccharide-type compounds resulting from cell secretion. Actually, Her et al. [30] found that the characteristics of the organic matter are more important for its fouling potential than the DOC concentration.

With the cells 1 month old, the TOC rejection gradually increased from $17 \%$ (0\% WRR) to $36 \%$ at $90 \%$ WRR (Fig. 12). The fouling potential of this water indicates high adsorption, cake formation or membrane pore blockage mechanisms, especially at higher recovery rates, which increase the membrane resistance and also the rejection. With the cells 3 months old, the TOC rejection at the beginning of the filtration exceeded the value found for the 1month-old cells ( $26 \%$ vs. $17 \%$ ) and had a rather insignificant increase with WRR (28\% for 90\% WRR).

The membrane fouling phenomenon and its relation with the organic and inorganic water matrices will be further addressed in a paper to follow.

\section{Conclusions}

This study demonstrated that ultrafiltration with a hollow-fibre cellulose acetate membrane of $100 \mathrm{kDa}$ cut-off is a safe barrier against cyanobacteria, producing water free from $M$. aeruginosa single cells (the smallest cyanobacterial cells and therefore the most difficult to remove) and with a turbidity below 0.1 NTU, even with feed chlorophyll-a concentrations as high as $60 \mu \mathrm{g} / \mathrm{L}$.

Regarding the UF effect onto cell lysis, data showed an increasing lysis with cell ageing, although the permeate quality was never deteriorated. In parallel to cell damage, an enhancement of microcystin rejection by the UF membrane was observed with cell ageing 
probably associated with the greater content of the older cultures in segregated AOM (mucopolysaccharides) and/or protein lysed AOM. Actually, preliminary experiments in the absence of background organics showed no rejection of microcystins by this hydrophilic UF membrane. Due to the existence of AOM-driven adsorption of microcystin onto the membrane surface, cell lysis evaluation based only on the time evolution of dissolved microcystin concentration in the feed and permeate underestimates this phenomenon, and a mass-balance equation was derived to compute the net contribution of adsorption and cell lysis. This methodology indicated the overall dominance of cell lysis over adsorption.

Results from UF concentration runs also indicated that the characteristics of the water background organics and inorganics, rather than their overall concentration, must govern the membrane fouling. In this study, a strong foulant behaviour (60\% normalised flux for $90 \%$ WRR) and an increase in the TOC rejection were observed for waters with 1-month-old culture, i.e. with polysaccharide-rich AOM in the presence of scaling multivalent ions, whereas no significant flux decline nor TOC rejection changes were observed for the analogous run performed with the culture 3 months old (proteinrich AOM with much lower content of multivalent ions).

In conclusion, UF ensured an absolute cell removal with no degradation of permeate quality. However, cell damage results advise prudence when considering the use of UF to treat algal-rich waters. In this case, to minimise cell lysis and membrane fouling UF may be preceded by a pre-treatment step of $C / F / S$ or $C / F / D A F$ (preferentially with enhanced coagulation for improved removal of cyanobacteria and membrane foulant AOM) and/or integrated with a process that efficiently removes the dissolved cyanotoxins and the AOM, e.g. powdered activated carbon adsorption.

\section{Acknowledgments}

The authors would like to thank the Portuguese Science and Technology Foundation, for providing a Ph.D. scholarship to Margarida Campinas (BD/10356/2002). Special thanks are also addressed to Águas do Algarve, S.A. (Portugal), for partially funding this project.

\section{References}

[1] A. Paralkar, J. Edzwald, J. Am. Water Works Assoc. 4 (1996) 143-154.

[2] J.-J. Chen, H.-H. Yeh, Water Sci. Technol.: Water Supply 6 (3) (2006) 79-88.
[3] J. Ma, J. Fang, L. Wang, J. Guo, Z. Chen, Water Sci. Technol.: Water Supply 6 (4) (2006) 145-152.

[4] K. Sivonen, G. Jones, in: WHO (Ed.), Toxic Cyanobacteria in Water: a Guide to Their Public Health Consequences, Monitoring and Management, E\& SPON, London, 1999, pp. 3.1-3.6.

[5] K. Himberg, A.-M. Keijola, L. Hiisvirta, H. Pyysalo, K. Sivonen, Water Res. 23 (8) (1989) 979-984.

[6] J. Pietsch, K. Bornmann, W. Schmidt, Acta Hydrochim. Hydrobiol. 30 (1) (2002) 7-15.

[7] M. Drikas, C. Chow, J. House, M. Burch, J. Am. Water Works Assoc. 2 (2001) $100-111$.

[8] S. Hrudey, M. Burch, M. Drikas, R. Gregory, in: World Health Organization (Ed.), Toxic Cyanobacteria in Water: a Guide to Their Public Health Consequences, Monitoring and Management, E\& SPON, London, 1999, pp. 9.1-9.9.

[9] C. Chow, J. House, M. Drikas, M. Burch, R. Velzeboer, Water Res. 33 (15) (1999) 3253-3262.

[10] M. Ribau Teixeira, M.J. Rosa, Sep. Purif. Technol. 52 (2006) 84-94.

[11] M. Ribau Teixeira, M.J. Rosa, Sep. Purif. Technol. 53 (2007) 126-134.

[12] C. Chow, S. Panglish, J. House, M. Drikas, M. Burch, R. Gimbel, J. Water Sci. Res. Tech. - Aqua 46 (6) (1997) 324-334.

[13] P. Mouchet, V. Bonnélye, J. Water Sci. Res. Tech. - Aqua 47 (3) (1998) 125-141.

[14] A. Gijsbertsen-Abrahamse, W. Schmidt, I. Chorus, S. Heijman, J. Membr. Sci. 276 (2006) 252-259.

[15] R.Y. Stanier, R. Kunisawa, M. Mandel, G. Cohen-Bazire, Bacteriol. Rev. 35 (2) (1971) 171-205.

[16] M. Campinas, M.J. Rosa, J. Colloid Interface Sci. 299 (2) (2006) 520-529.

[17] M. Pivokonsky, O. Kloucek, L. Pivokonska, Water Res. 40 (2006) 3045-3052.

[18] J. Bartram, M. Burch, I. Falconer, G. Jones, T. Kuiper-Goodman, in: World Health Organization (Ed.), Toxic Cyanobacteria in Water: a Guide to Their Public Health Consequences, Monitoring and Management, E\& SPON, London, 1999, pp. 1.1-1.6.

[19] G. Crozes, J. Jacangelo, C. Anselme, J. Laîné, J. Membr. Sci. 124 (1) (1997) 63-76.

[20] C.J. Lorenzen, Limnol. Oceanogr. 12 (2) (1967) 343-346.

[21] J. Meriluoto, L. Spoof, SOP: extraction of microcystins in biomass filtered on glass-fibre filters or in freeze-dried cyanobacterial biomass, in: J. Meriluoto, G. Codd (Eds.), Toxic Cyanobacterial Monitoring and Cyanotoxin Analysis, Abo Akademi University Press, Finland, 2005.

[22] J. Meriluoto, L. Spoof, SOP: solid phase extraction of microcystin in water samples, in: J. Meriluoto, G. Codd (Eds.), Toxic Cyanobacterial Monitoring and Cyanotoxin Analysis, Abo Akademi University Press, Finland, 2005.

[23] J. Meriluoto, L. Spoof, SOPL: analysis of microcystins by high-performance liquid chromatography with photodiode-array detection, in: J. Meriluoto, G. Codd (Eds.), Toxic Cyanobacterial Monitoring and Cyanotoxin Analysis, Abo Akademi University Press, Finland, 2005.

[24] A. Vlaski, A. Breemen, G. Alaerts, J. Water Sci. Res. Tech. - Aqua 45 (5) (1996) 253-261.

[25] J. Ottoson, A. Hansen, B. Bjorlenius, H. Norder, T. Stenstrom, Water Res. 40 (2006) 1449-1457.

[26] A.-S. Jönsson, J. Lindau, R. Wimmerstedt, J. Brinck, B. Jönsson, J. Membr. Sci. 135 (1997) 117-128.

[27] M. Ribau Teixeira, M.J. Rosa, Sep. Purif. Technol. 46 (2005) 192-201.

[28] J. Lee, H. Walker, Environ. Sci. Technol. 40 (2006) 7336-7342.

[29] R. De Philippis, C. Sili, R. Paperi, M. Vincenzini, J. Appl. Phyc. 13 (2001) 293-299.

[30] N. Her, G. Amy, H.-R. Park, M. Song, Water Res. 38 (2004) 1427-1438.

[31] N. Lee, G. Amy, J.-P. Croué, Water Res. 40 (2006) 2357-2368. 